\title{
ELASTIC PROPERTIES AND DETERMINATION OF ELASTIC CONSTANTS OF NICKEL-BASE SUPERALLOYS BY A FREE-FREE BEAM TECHNIQUE
}

\author{
W. Hermann", H.G. Sockel*, J. Han ${ }^{* *}$, and A. Bertram ${ }^{* * *}$ \\ * Institut für Werkstoffwissenschaften, Lehrstuhl I, Universität Erlangen-Nürnberg, Martensstr. 5, D-91058 Erlangen, F.R. Germany, \\ - Bundesanstalt für Materialforschung und -prüfung, Unter den Eichen 87, D-12205 Berlin, F.R. Germany, \\ ${ }^{* * *}$ Institut für Mechanik, Otto-von-Guericke-Universität, Universitätsplatz 2, D-39106 Magdeburg, F.R. Germany,
}

\begin{abstract}
The clastic properties of several monocrystalline and textured Nickel-base alloys were determined as a function of orientation in single crystals and of direction in textured materials by a dynamic resonance technique between $20^{\circ} \mathrm{C}$ and $1200^{\circ} \mathrm{C}$. For the quantitative description of the elastic behavior of anisotropic solids the elastic single crystal constants, the texture, and the orientation are needed. The texture of polycrystalline materials is described by the orientation distribution function (ODF). In single crystals the orientation is given by the Eulerian angles. The determination of the elastic constants from single crystal measurements by a regression and a Finite Element (FE) method is shown in this paper to be very accurate. A new regression method allows the determination of single crystal elastic constants from strongly textured materials. This method is based on the measured elastic moduli in different directions with regard to the direction of rolling, growth or recrystallization. The evaluation of the elastic constants by regression and FE methods and the results for several Nickelbase superalloys are presented and discussed.
\end{abstract}

\section{$\underline{\text { Introduction }}$}

Advanced industrial gas turbines must be operated at increasing high temperatures to improve the efficiency and to enhance power output. In order to meet the requirements for this application, turbine blades are manufactured from monocrystalline alloys or alloys with special textures, such as directionally solidified (DS) alloys having fibre textures, or directionally recrystallized (DR) alloys exhibiting sheet textures. With a decreasing number of transverse grain boundaries, improved thermal fatigue resistance and creep strength of these materials are achieved, allowing higher stresses and temperatures in service. Nickel-base superalloys with $\gamma^{\prime}-\left(\mathrm{Ni}_{3}(\mathrm{Al}, \mathrm{Ti})\right.$ ) precipitates, such as CMSX-4, CMSX-6, IN 738 LC or SRR 99 are of great interest for these applications.

For the design of statically and dynamically loaded components, the knowledge of the elastic moduli and their variations with

Superalloys 1996

Edited by R. D. Kissinger, D. J. Deye, D. L. Anton,

A. D. Cetel, M. V. Nathal, T. M. Pollock, and D. A. Woodford

The Minerals, Metals \& Materials Society, 1996 temperature and orientation or direction, respectively, is a fundamental requirement, especially for the analyses of vibrations, strength, fracture, or stability of structures. The elastic moduli (Young's modulus E and shear modulus $\mathrm{G}$ ) of anisotropic solids show a strong variation with orientation in single crystals and with direction in textured materials (Fig. 1 and 2). Therefore, it is necessary to describe the elastic behaviour of each anisotropic material by the determination of the orientation- or directionindependent elastic constants. Furtheron mathematical descriptions of the elastic properties as functions of the texture and the direction are needed. The direction-independent elastic constants (elastic single crystal constants or elastic material constants) are the elastic compliances $S_{i j}$ and the elastic stiffnesses $C_{i j}$ in Hooke's law. These constants can be determined with high accuracy by resonant frequency measurements with regression meth. ods or with a newly developed FE analysis.

\section{$\underline{\text { Materials }}$}

Out of the great number of $\gamma$ '-precipitation hardened Ni-base alloys investigated by the authors, measurements on SRR 99, CMSX-4, CMSX-6 and IN 738 LC, and also on near- $\gamma^{\prime} \mathrm{Ni}_{3} \mathrm{Al}$ and on a precipitation-free near- $\gamma$ matrix material are presented. The elemental compositions of these alloys are given in Table I.

The $\gamma$ '-precipitation hardened Nickel-base alloys IN 738 LC, SRR 99, CMSX-4 and CMSX-6 were obtained as monocrystalline sheets. Several cylindrical specimens of about $4-5 \mathrm{~mm}$ in diameter and $40-50 \mathrm{~mm}$ in length were machined. The orientations of these single crystal specimens are distributed statistically in the standard stereographic triangle. In addition the alloy IN 738 LC was available in form of a directionally solidified turbine blade with a mean grain diameter of $4 \mathrm{~mm}$, and a grain length larger than $100 \mathrm{~mm}$. This DS material exhibits a strong $<100>$-fibre texture. Several specimens were machined in such a way that the angle between the specimen axis and the fibre axis was varied between $0^{\circ}$ and $90^{\circ}$ in steps of $15^{\circ}$. 
Table I: Elemental composition of the investigated Nickel-base alloys in weight-\%.

\begin{tabular}{|c|c|c|c|c|c|c|c|c|c|c|c|c|}
\hline & $\mathrm{Co}$ & $\mathrm{Ta}$ & $\mathrm{Cr}$ & W & $\mathrm{Al}$ & $\operatorname{Re}$ & $\mathrm{Ti}$ & Mo & $\mathrm{Hf}$ & $\mathrm{Fe}$ & $\mathrm{Nb}$ & $\mathrm{Ni}$ \\
\hline SRR 99 & 19.3 & 2.9 & 9.0 & 9.5 & 5.5 & - & 1.8 & - & - & 1.0 & 0.7 & bal. \\
\hline CMSX-4 & 9.5 & 6.5 & 6.4 & 6.3 & 5.7 & 2.9 & 1.0 & 0.6 & 0.1 & 0.1 & 0.1 & bal. \\
\hline CMSX-6 & 5.0 & 2.0 & 10.0 & - & 4.9 & - & 4.8 & 3.0 & - & - & - & bal. \\
\hline IN $738 \mathrm{LC}$ & 8.6 & 1.9 & 16.0 & 2.7 & 3.4 & - & 3.4 & 1.8 & - & 0.1 & 0.9 & bal. \\
\hline Matrix alloy & 16.7 & - & 15.8 & 8.0 & - & 5.0 & - & 1.8 & - & - & - & bal. \\
\hline
\end{tabular}

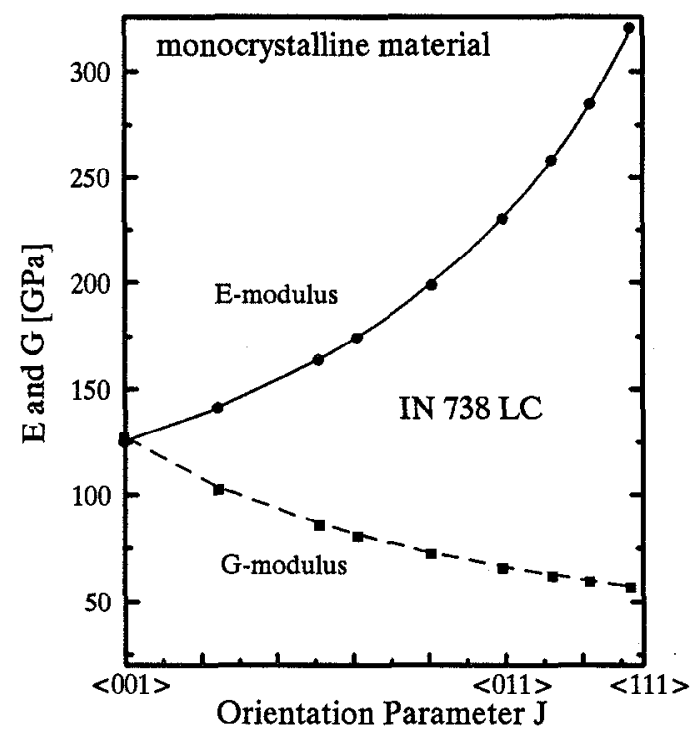

Figure 1: Young's modulus $\mathrm{E}$ and shear modulus $\mathrm{G}$ of monocrystalline IN $738 \mathrm{LC}$ as a function of the orientation parameter $\mathrm{J}$ (equ. 8), describing the orientation.

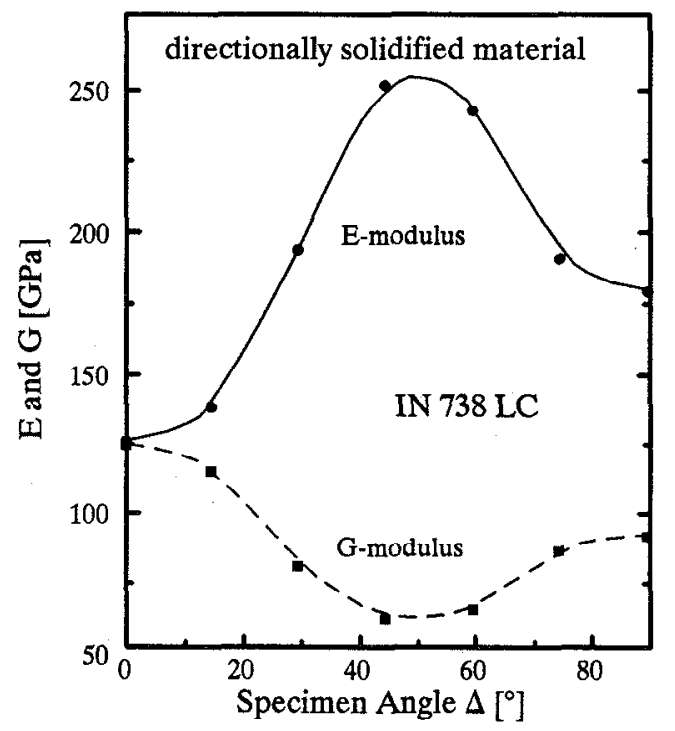

Figure 2: Young's modulus $\mathrm{E}$ and shear modulus $\mathrm{G}$ of directionally solidificd IN $738 \mathrm{LC}$ as a function of the angle $\Delta$ between the specimen axis and the direction of solidification.

\section{Experimental}

For the determination of the elastic properties from resonant frequency measurements a modified Förster resonance technique is used. Long thin rods with approximately $50 \mathrm{~mm}$ in length and $5 \mathrm{~mm}$ in diameter are excited to vibrations by piezo-electrical transducers and the resonant frequencies are measured (Fig. 3). The transducers are coupled to the specimen by suspension of the rod into carbon wire loops. By the Gain-Phase Analyzer the amplitude and the phase angle are measured as a function of the applied frequency. In the case of resonance, a maximum in amplitude and a characteristic phase shift are measured. The measurements were carried out in vacuum in the 4 to $150 \mathrm{kHz}$ frequency range between $20^{\circ} \mathrm{C}$ and $1250^{\circ} \mathrm{C}$. The temperature was controlled by a PLPLRh-thermocouple located $1 \mathrm{~mm}$ away from the middle of the specimen.

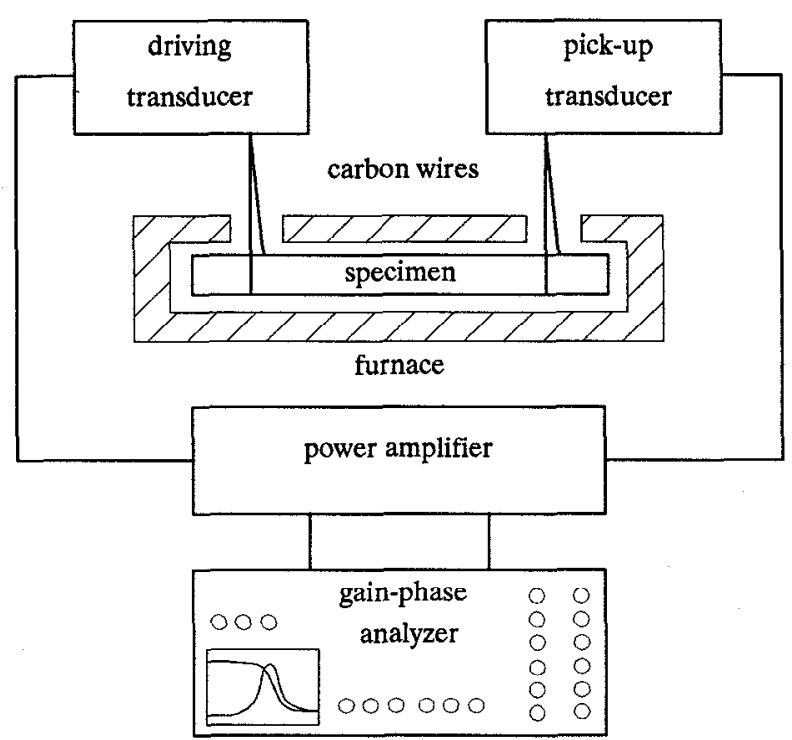

Figure 3: Schematic representation of the experimental equipment for measuring the resonant frequencies.

Three vibrational modes, the flexural, longitudinal and torsional, are excited in the fundanental vibrations and in several overtones. Flexural and longitudinal vibrations supply information about the Young's modulus $\mathrm{E}(\mathrm{T})$, and the torsional vibrations about the shear modulus $\mathrm{G}(\mathrm{T})$. From the measured resonant fre- 
quencies the Young's modulus and the shear modulus are calculated via the following theoretical relationships $/ 1,2,3 /$ :

$$
\begin{gathered}
E(T)=\frac{4 \cdot \pi^{2} \cdot \rho(T) \cdot l^{4}(T) \cdot \int_{n, f l e x}^{2}(T)}{\chi^{2}(T) \cdot\left(m_{n}\right)^{4}} \cdot K_{b}, \\
G(T)=4 \cdot \rho(T) \cdot l^{2}(T) \cdot\left(f_{n, t o r s}^{2}(T) / n^{2}\right) \cdot K_{t},
\end{gathered}
$$

where $\rho(T)$ is the density, $I(T)$ the length, $\chi(T)$ the radius of inertia, $n$ the order of vibration, and $f_{n}(T)$ the resonant frequency of the $n$-th mode of vibration of flexure or torsion. $K_{b}, K_{t}$, and $m_{n}$ are vibration mode dependent correction factors, tabulated in $/ 1$.

For measurements at temperatures above $20^{\circ} \mathrm{C}$ the specimen dimension and the density had to be corrected by the coefficient of thermal expansion.

\section{Elastic Behaviour of Anisotropic Solids with Cubic Crystal Structure}

\section{Single Crystals}

The proportionality of stress and strain is described by the two forms of the generalized Hooke's law. It relates the stress vector $\sigma$ to the strain vector $\varepsilon$ by the equations /4/

$$
\begin{aligned}
& \sigma_{i}=\sum C_{i j} \cdot \varepsilon_{j}, \\
& \varepsilon_{i}=\sum S_{i j} \cdot \sigma_{j},
\end{aligned}
$$

where $C_{i j}$ is the stiffness matrix and $S_{i j}$ is the compliance matrix. The matrices $C_{i j}$ and $S_{i j}$ have in general twenty-one independent components with respect to an arbitrarily selected coordinate system, but this number can be reduced drastically in the presence of crystal symmetries. For instance, single crystals with cubic, hexagonal and orthorhombic symmetries have three, five and nine independent elastic stiffnesses $C_{i j}$ (compliances $S_{i j}$ ), respectively. In the case of cubic crystal symmetry the three independent elastic single crystal constants are $S_{11}, S_{12}$ and $S_{44}$ or $C_{11}, C_{12}$ and $C_{44}$. The stiffnesses $C_{i j}$ can be calculated from the compliances $S_{i j}$ and vice versa $/ 5 /$.

If the single crystal specimens are long and thin rods, then orientation-dependent elastic moduli are connected to the compliances by the following equations $/ 4,6 /$ :

$$
\begin{gathered}
E_{m e s}(\theta, \varphi)=\left[S_{11}-2 S J\right]^{-1}, \\
G_{m e s}(\theta, \varphi)=\left[\left(S_{44}-4 S J\right) \cdot(1-\delta)\right]^{-1},
\end{gathered}
$$

where $\mathrm{E}_{\mathrm{mes}}(\theta, \varphi)$ and $\mathrm{G}_{\mathrm{mes}}(\theta, \varphi)$ are the measured Young's and shear modulus for a given orientation, $\theta$ and $\varphi$ are the Eulerian angles according to Fig. 4 . The factor $\delta$ corrects coupling effects between torsion and bending $/ 6,7 / . \mathrm{S}$ and the orientation parameter $\mathbf{J}$ are given by the following equations:

$$
S=S_{11}-S_{12}-S_{44} / 2
$$

$$
J=\sin ^{2} \theta \cdot \cos ^{2} \theta+\frac{1}{8} \sin ^{4} \theta \cdot(1-\cos (4 \varphi))
$$

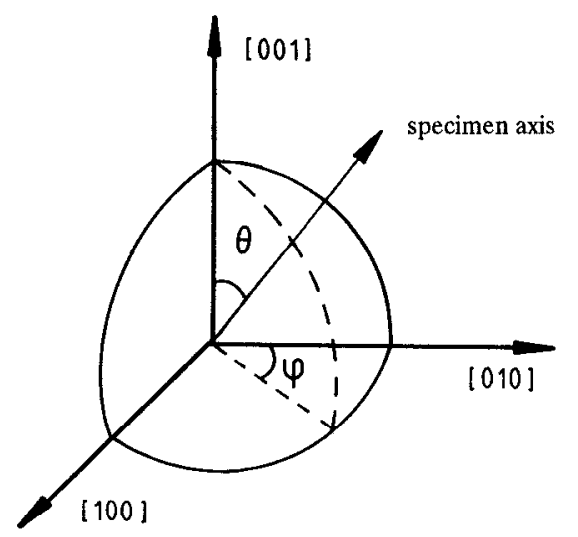

Figure 4: Definition of the Eulerian angles $\theta$ and $\varphi$.

\section{$\underline{\text { Textured Materials }}$}

A description of the elastic behavior of a textured material is based on a consideration of the symmetry of the whole polycrystalline aggregate. Fibre textured materials, e.g. directionally solidified Nickel-base alloys, exhibit hexagonal symmetry, while rolled sheets can be described by assuming an orthorhombic symmetry. Hence, the elastic behavior of these textured materials is determined by five or nine elastic polycrystal constants $S_{i j}^{p c}$ and $\mathrm{C}_{\mathrm{ij}}^{\mathrm{pc}}$ in the cases of hexagonal and orthorhombic symmetry, respectively. Then Hooke's law can be expressed by equations (9) and $(10)$, where the polycrystal constants of the textured material correlate the mean stresses $\bar{\sigma}$ with the mean strains $\bar{\varepsilon} \cdot \mathrm{S}_{\mathrm{ij}}^{\mathrm{v}}$ and $\mathrm{C}_{\mathrm{ij}}^{\mathrm{V}}$ are the polycrystal constants according to Voigt /4/ and Reuss /8/, respectively.

For the condition of constant strain in all grains an upper bound of the elastic properties according to Voigt is obtained, while for the condition of constant stress in all grains one gets a lower bound of the elastic properties according to Reuss: 


$$
\begin{aligned}
& \bar{\sigma}_{i}=\sum C_{i j}^{V} \cdot \varepsilon_{j}, \\
& \bar{\varepsilon}_{i}=\sum S_{i j}^{R} \cdot \sigma_{j} .
\end{aligned}
$$

The mean values of these upper and lower bounds given by

$$
S_{i j}^{H}=\frac{1}{2}\left[S_{i j}^{R}+S_{i j}^{V}\right]
$$

according to Hill /9/ are very close to the real elastic properties of the textured material. $S_{i j}^{\vee}$ and $C_{i j}^{\vee}$ are connected via $S_{i j}^{\vee}=\left[C_{i j}^{V}\right]^{-1}$.

These polycrystal constants are related to the single crystal constants by the orientation distribution function (ODF) of the texture by equations given in the appendix (A1 and A2) for hexagonal texture symmetry $/ 10,11 /$. The relations between the direction-dependent elastic moduli $\mathrm{E}$ and $\mathrm{G}$ and the elastic polycrystal constants $S_{i j}{ }^{p c}$ are given by equations (12) and (13) for hexagonal symmetries as in the fibre textures:

$$
\begin{array}{r}
E(\theta)=\left[S_{11}^{p c} \sin ^{4} \theta+S_{33}^{p c} \cos ^{4} \theta+\right. \\
\left.+\left(2 S_{13}^{p c}+S_{44}^{p c}\right) \sin ^{2} \theta \cdot \cos ^{2} \theta\right]^{-1}, \\
G(\theta)=\left[S_{44}^{p c}+\left(S_{11}^{p c}-S_{12}^{p c}-\left(S_{44}^{p c} / 2\right)\right) \sin ^{2} \theta+2\left(S_{11}^{p c}+\right.\right. \\
\left.\left.+S_{33}^{p c}-2 S_{13}^{p c}-S_{44}^{p c}\right) \cos ^{2} \theta \sin ^{2} \theta\right]^{-1} \cdot[1-\kappa]^{-1}
\end{array}
$$

where $\Delta$ denotes the angle between the specimen axis and the fibre axis.

Using the equations (12) and (13) with the polycrystal constants according to Voigt, Reuss or Hill we obtain upper and lower bounds of the elastic moduli or the Hill mean values. Fig. 5 shows the dependence of Young's and shear modulus versus the angle $\Delta$ between the specimen axis and the fibre axis of directionally solidified IN 738 LC. The Voigt-Reuss-Hill values calculated according to eqns. (12), (13), (A1), (A2) are compared with the measured ones. The Hill mean values, based on the elastic constants determined from single crystal measurements and the ODF show a good agreement with the measurement data.

\section{Determination of Elastic Constants}

As mentioned above the knowledge of the elastic single crystal constants is very important to describe the elastic behavior of anisotropic solids. For this reason several methods have been developed to determine the elastic constants from measured

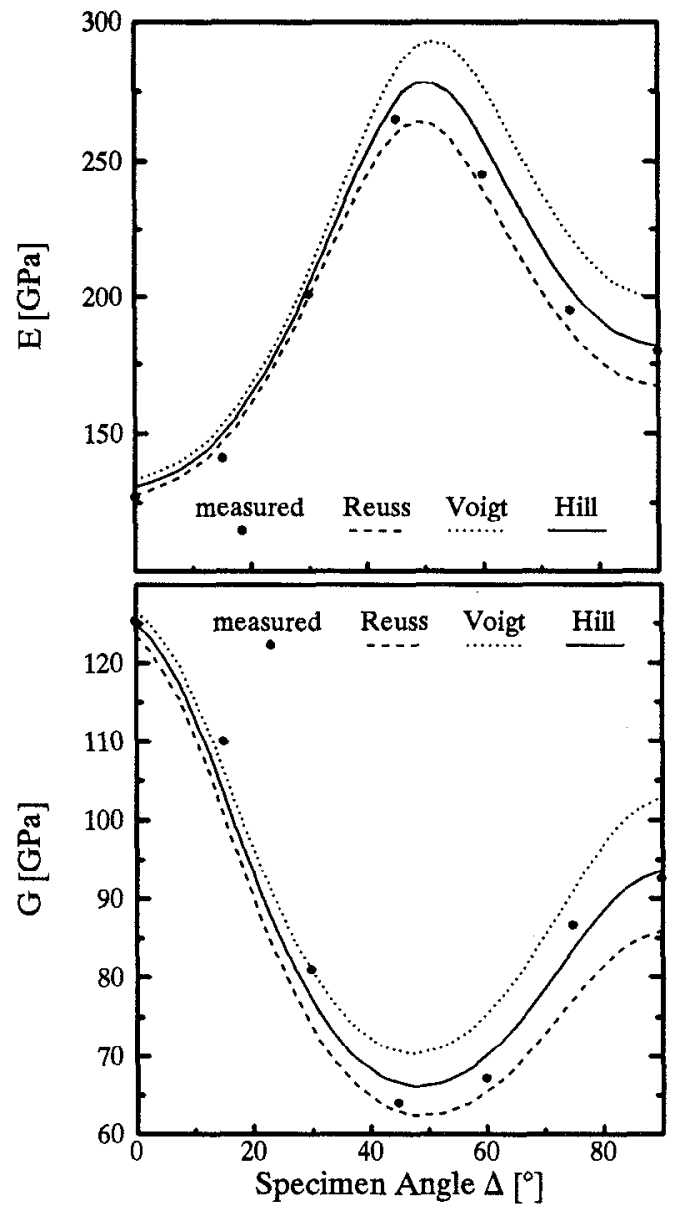

Figure 5: Measured Young's and shear modulus and calculated Voigt-Reuss-Hill values for IN 738 LC DS, as a function of the angle $\Delta$ between the fibre axis and the specimen axis.

resonant frequencies. In the following the determination of the elastic constants from resonance measurements of single crystals and of textured materials will be presented. Two different methods are used, based on regression and on Finite Elements (FE), respectively.

\section{$\underline{\text { Single Crystals }}$}

The regression method for cubic single crystals, based on the equations (5) to (8), is the most simple way to determine the elastic compliances. According to them, the reciprocal values of the measured moduli, $\left(\mathrm{E}_{\mathrm{mes}}\right)^{-1}$ and $\left(\mathrm{G}_{\text {mes }} \cdot(1-\delta)\right)^{-1}$, of several specimens, each with different orientation, are plotted versus the orientation parameter $\mathrm{J}$, given in equation (8), (Fig. 6). A linear regression with respect to $J=0$ leads to the elastic constants $S_{11}$ and $S_{44}$, while $S_{12}$ can be calculated by equation (7) from the slope of the regression lines. The slope of the regression lines from measured reciprocal elastic moduli versus $J$ is equal to $-2 S$ and $4 S$, respectively. 


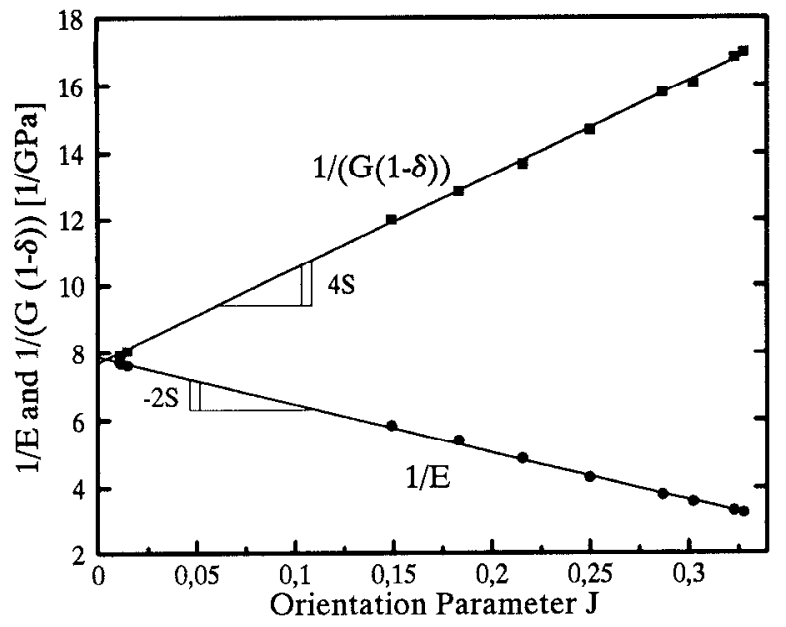

Figure 6: Determination of $S_{11}, S_{44}$ and $S_{12}$ by linear regression from single crystal measurements for the alloy CMSX-4.

Using the Finite Element Method (FEM), the resonant frequencies of a cylindrical specimen are calculated by an FE-model for given elastic constants. The specimen is modelled by 16 isoparametric three-dimensional 20-node-elements / $12 /$. The desired resonant frequencies are obtained from solutions of the following corresponding eigenvalue equations:

$$
\left(-\omega_{i}^{2} M+K\right) \cdot u_{i}=0 ; \quad i=1,2, \ldots,
$$

where $\omega_{i}$ and $u_{i}$ are the $i$-th natural frequency and mode, $\mathbf{M}$ and $\mathrm{K}$ are the mass and stiffness matrices of the FE-model, respectively.

The strategy for the determination of the elastic constants and the orientation is the adjustment of these constants in an optimization procedure, where the differences between the measured and the calculated frequencies of several specimens are minimized. The eigenvalue equations (14) are solved by the FEM code ADINA /13/. The optimizer is from MINIPACK /14/. It uses a modified Levenberg-Marquard algorithm. In every iteration step of the optimization procedure, the calculated frequencies must be assigned to the measured ones. This is carried out by the use of a frequency assignment algorithm which is based on the orthogonality of the natural modes. In the optimization procedure also the orientation of the specimens can be determined beside the elastic constants. The details about the frequency assignment algorithm and the numerical simulation of the dependence of the resonant frequencies on the orientation and on the elastic constants are given in reference $/ 15,16 /$.

\section{Textured material}

Problems can arise in obtaining the elastic constants of the single crystal in the cases where the latter is difficult to grow, expensive or cannot be prepared at all, as for instance in the case of ODSalloys. In all these cases the elastic constants of the single crystal have to be determined from measurements on textured polycrystalline material. This determination is only possible if the polycrystalline material exhibits elastic properties which depend on the direction. These properties have to be measured in several directions with regard to the direction of rolling, growth or recrystallization. From such experimental results the elastic constants of the single crystal can be calculated by connecting the properties of the textured polycrystalline and the monocrystalline material as shown above. Using the concept of Hill, a new empirical evaluation method allows the determination of the elastic single crystal constants from measurements on texturcd matcrial.

This method is formally based on the relations between the elastic properties and the orientation parameter $J$ for a single crystal of cubic crystal structure $/ 17 \%$. In the following this method is presented for fibre textured material. From the input data, which are the coefficient of the ODF and approximately assumed elastic constants $S_{11}, S_{12}$ and $S_{44}$, the five elastic constants $S_{i j}{ }^{H}$ for hexagonal symmetry are calculated by equation (12), (13), (A1) and (A2). Then these are used for the determination of theoretical values $E(\Delta)$ and $G(\Lambda)$, where $\Delta$ denotes the specimen angle as introduced above. In the next step these values are introduced into the equations (15) and (16) for the determination of theoretical orientation parameters $\mathrm{J}_{\mathrm{e}}(\Delta)$ and $\mathrm{J}_{\mathrm{g}}(\Delta)$ :

$$
\begin{gathered}
1 / E(\Delta)=S_{11}-2 S J_{e}(\Delta), \\
1 /[G(\Delta)(1-\delta)]=S_{44}+4 S J_{g}(\Delta) .
\end{gathered}
$$

After the calculation of $\mathrm{J}_{\mathrm{e}}(\Delta)$ and $\mathrm{J}_{\mathrm{g}}(\Delta)$ the measured moduli are introduced in the equations (15) and (16). A linear regression with respect to $J_{e}(\Delta)$ and $J_{g}(\Delta)$ leads to the compliances of the single crystal, analogous to the regression in the case of cubic single crystals. Using these single crystal constants as new input data for the next iteration step, improved values of $J_{e}(\Delta)$ and $J_{g}(\Delta)$ can be determined as described above. It is necessary to repeat this procedure until there is no further significant change in the calculated constants from the (n-1)-th and $n$-th cyclus. In practice not more than five iteration steps are necessary.

The Finite Element Method can also be applied to sheet or fibre textured material. According to the regression method it is assumed that textured material macroscopically exhibits a hexagonal or orthorhombic symmetry. In these cases five or nine elastic constants must be adjusted /18,19/. In the FE-model of the specimen the exact macroscopic constilutive law for the elastic anisotropic material is used. This method can be regarded as a suitable averaging method which docs not use any restrictions on the distributions of the stresses or the strains and any prior knowl- 


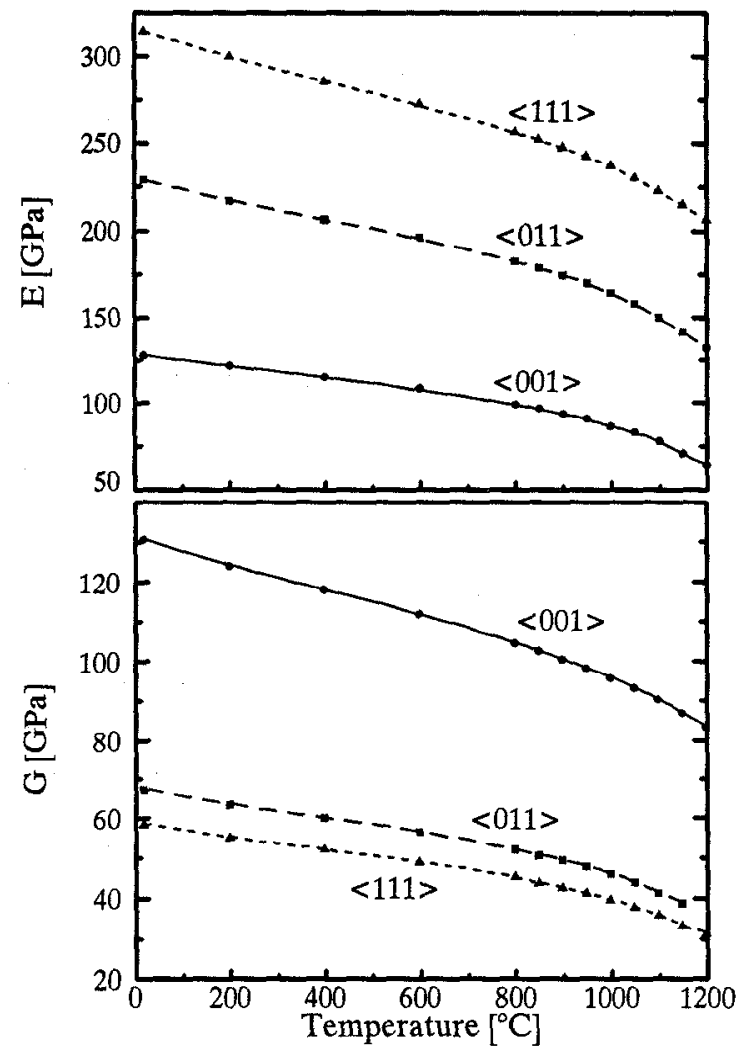

Figure 7: Young's and shear modulus for three different monocrystalline specimens of the alloy CMSX-4.

edge about the orientation distribution of a textured alloy. Unfortunately, the successful determination of the elastic single crystal constants can be carried out only in the case of single crystals or strongly fibre textured materials. In the other cases only the elastic polycrystal constants depending on the texture can be determined.

\section{Results and Discussion}

\section{Elastic Moduli}

The elastic moduli of several monocrystalline specimens with different oricntations of the alloys SRR 99, CMSX-6, CMSX-4 and IN $738 \mathrm{LC}$ were determined between $20^{\circ} \mathrm{C}$ and $1200^{\circ} \mathrm{C}$. As an example Figure 7 shows the measured Young's and shear moduli in $\langle 001\rangle-$, $<011\rangle-$ and $<111\rangle$-direction as a function of the temperature for the alloy CMSX-4. Similar orientation dependencies of the elastic moduli were observed for all other monocrystalline Ni-base alloys.

Young's and shear modulus in Figure 7 show a linear decrease with temperature up to about $900^{\circ} \mathrm{C}$ and a very strong decrease between $900^{\circ} \mathrm{C}$ and $1100^{\circ} \mathrm{C}$. Extensive investigations of the damping behaviour of the alloy CMSX-4 reveals two different damping maxima in the temperature range in which the strong decrease of the elastic moduli occurs /20/ (Fig. 8).

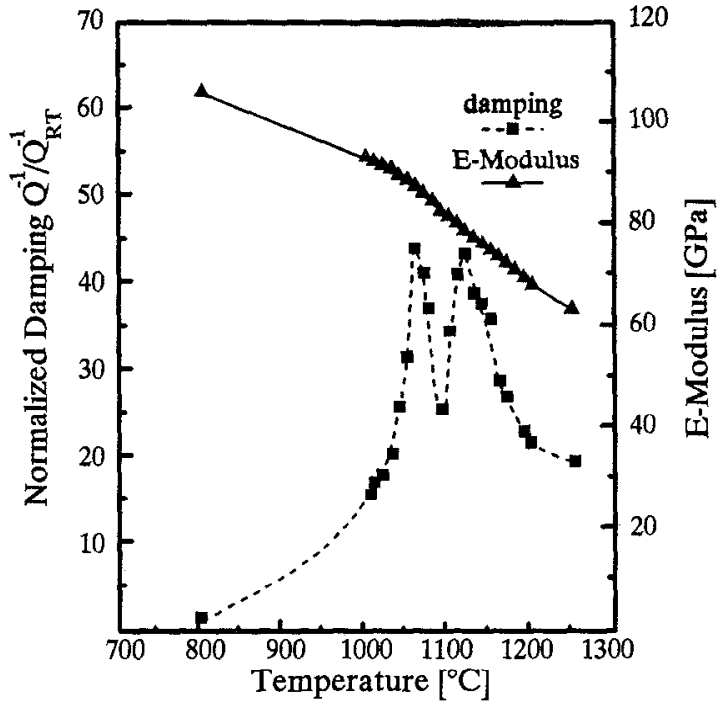

Figure 8: Young's modulus and normalized damping for the monocrystalline alloy CMSX-4.

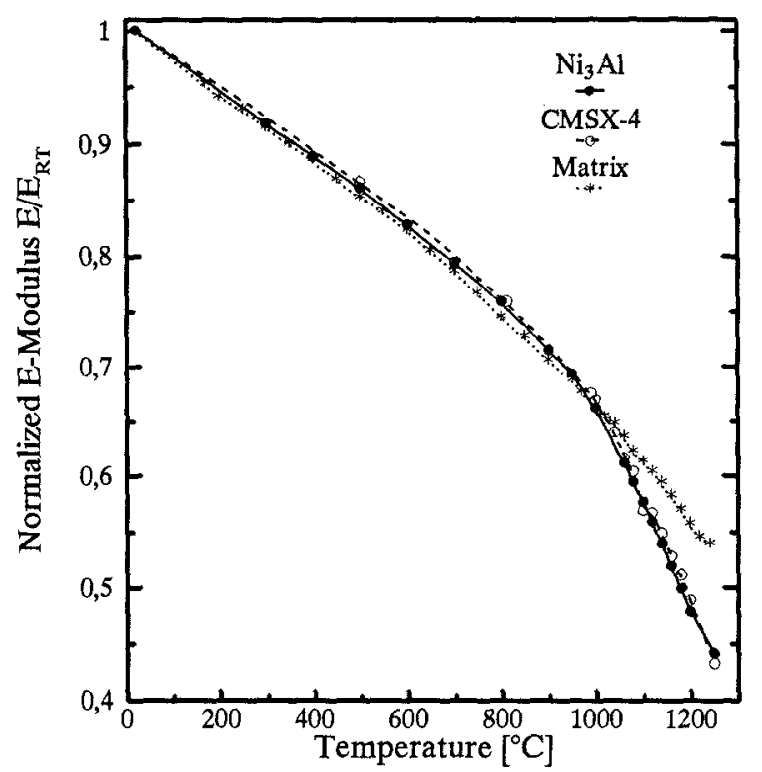

Figurc 9: Normalized Young's moduli as a function of the temperature for $\mathrm{CMSX}-4, \mathrm{Ni}_{3} \mathrm{Al}$ and the matrix material.

Further investigations performed on precipitation-free material, which is near to the composition of the $\gamma$-matrix of CMSX-4 121 , and on ordered $\mathrm{Ni}_{3} \mathrm{Al}$, which is near to the composition of the $\gamma^{\prime}$-precipilates, leads to the assumption, that these damping maxima are caused by diffusion processes in the $\gamma^{\prime}$-phase $/ 20 \%$.

From Figure 9 it is clearly visible, that the temperature dependence of the normalized Young's inoduli of CMSX-4 and $\mathrm{Ni}_{3} \mathrm{Al}$ agree very well, while for the $\gamma^{3}$-free matrix material no stronger modulus decrease at higher temperatures was found. This indicates that the stronger modulus decrease is caused by the $\gamma^{\prime}$ phase. Further details about the danping behaviour of Ni-base alloys are published in $120 \%$. 


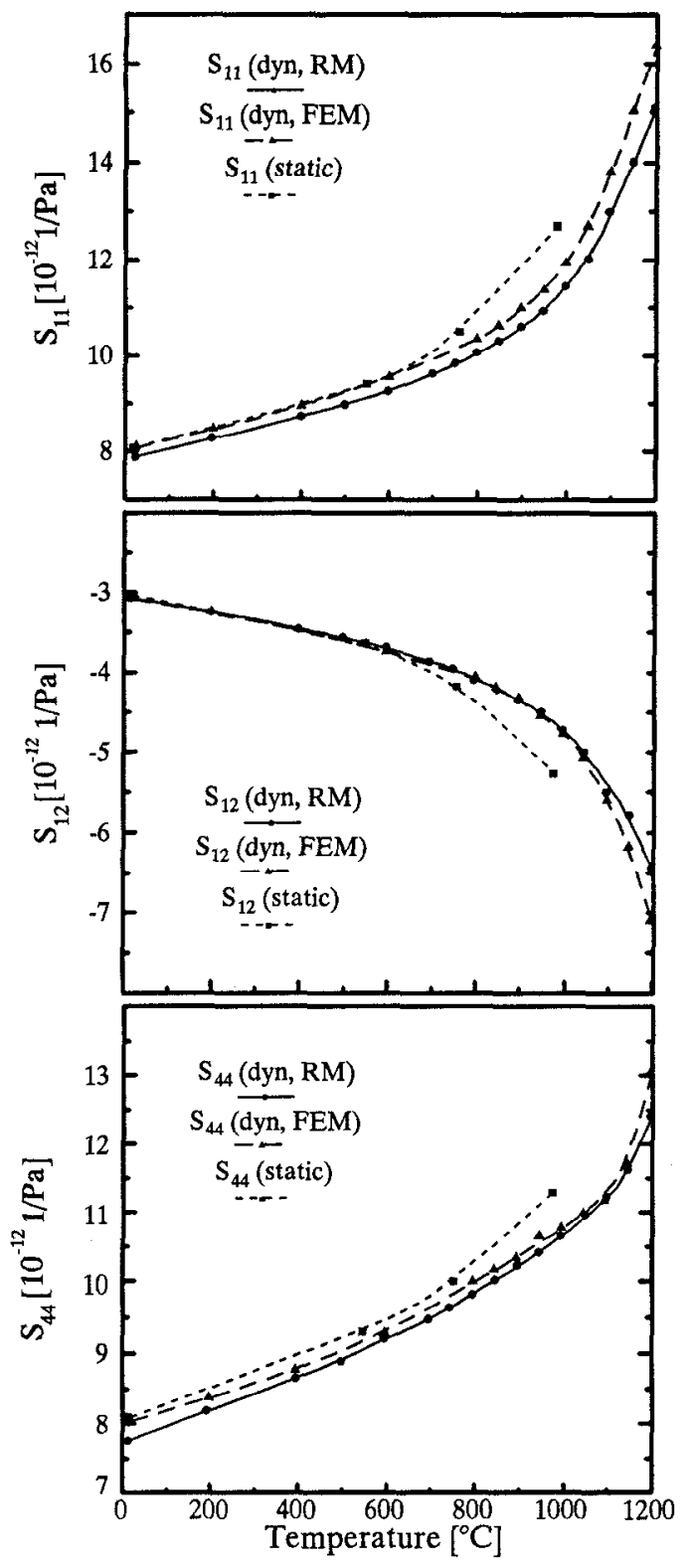

Figure 10: Elastic compliances $S_{11}, S_{12}$ and $S_{44}$ for the Ni-base alloy SRR 99.

\section{Elastic Constants}

The elastic compliances $S_{\mathrm{ij}}$ of the alloys CMSX-4, CMSX-6 and SRR 99 were determined from the measured resonant frequencies of several monocrystalline specimens by the regression - and the FE-method. In order to test the accuracy of these methods the evaluated constants $S_{11}, S_{12}$ and $S_{44}$ of the alloy SRR 99 are compared in Figure 10. In addition the data obtained from tensile tests up to $980^{\circ} \mathrm{C}$ are also included in Figure 10. The comparison of the constants $S_{i j}$ of different independent origins shows good agreement between them. The deviations lie in the range of $5 \%$ percent. Only at higher temperatures the constants from static tests show deviations up to $10 \%$, which is probably due to measurement effects.

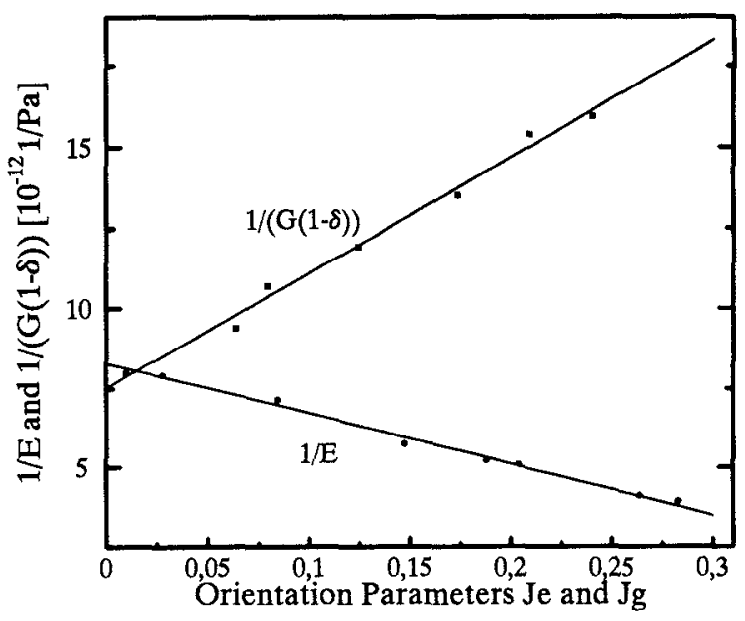

Figure 11: Determination of the elastic single crystal constants from measurements for fibre textured material of IN $738 \mathrm{LC}$.

In order to determine the elastic single crystal constants from textured material measurements according to the regression method described ahove, $<100>$-fibre textured IN $738 \mathrm{I}, \mathrm{C}$. was investigated. In Figure 11 the experimentally determined $[\mathrm{E}(\Delta)]^{-1}$ and $[G(\Delta)(1-\delta)]^{-1}$ of the textured material at room temperature are plotted versus the calculated $J_{c}(\Delta)$ and $J_{g}(\Delta)$, respectively. The plotted properties exhibit a good linear dependence on $J_{c}(\Delta)$ or $\mathrm{J}_{\mathrm{g}}(\Delta)$, respectively.

Figure 12 shows a comparison of elastic compliances $S_{11}, S_{12}$ and $S_{44}$ of IN $738 \mathrm{LC}$ determined from $<100>$-fibre texture and from single crystal measurements. The comparison of the constants $S_{i j}$ of different independent origins shows good agreement between them. The deviations lie in the range of $5 \%$ percent. This result confirms the high accuracy of the $S_{i j}$ values obtained from the investigation of textured materials by the new regression method.

In Figure 13 the elastic compliances of the alloys CMSX-4, C.MSX-6, SRR 99 and IN 738 are shown as a function of the temperature. The constants of these four alloys are very similar, with deviations lieing in the range of $10 \%$. Hence, the elastic constants of most of the Ni-base alloys can be regarded as nearly identical.

\section{$\underline{\text { Conclusions }}$}

The elastic moduli (Young's modulus $\mathrm{E}$ and shear modulus $\mathrm{G}$ ) of anisotropic materials exhibit a strong variation with orientation, direction and temperature. They were measured by a modified Förster resonance method between $25^{\circ} \mathrm{C}$ and $1200^{\circ} \mathrm{C}$. At temperatures between $900^{\circ} \mathrm{C}$ and $1100^{\circ} \mathrm{C}$ the elastic moduli of all investigated $\mathrm{Ni}$-Base alloys show a strong decrease, which is most probably caused by diffusion processes in the $\gamma^{\prime}$-precipitation phase. 


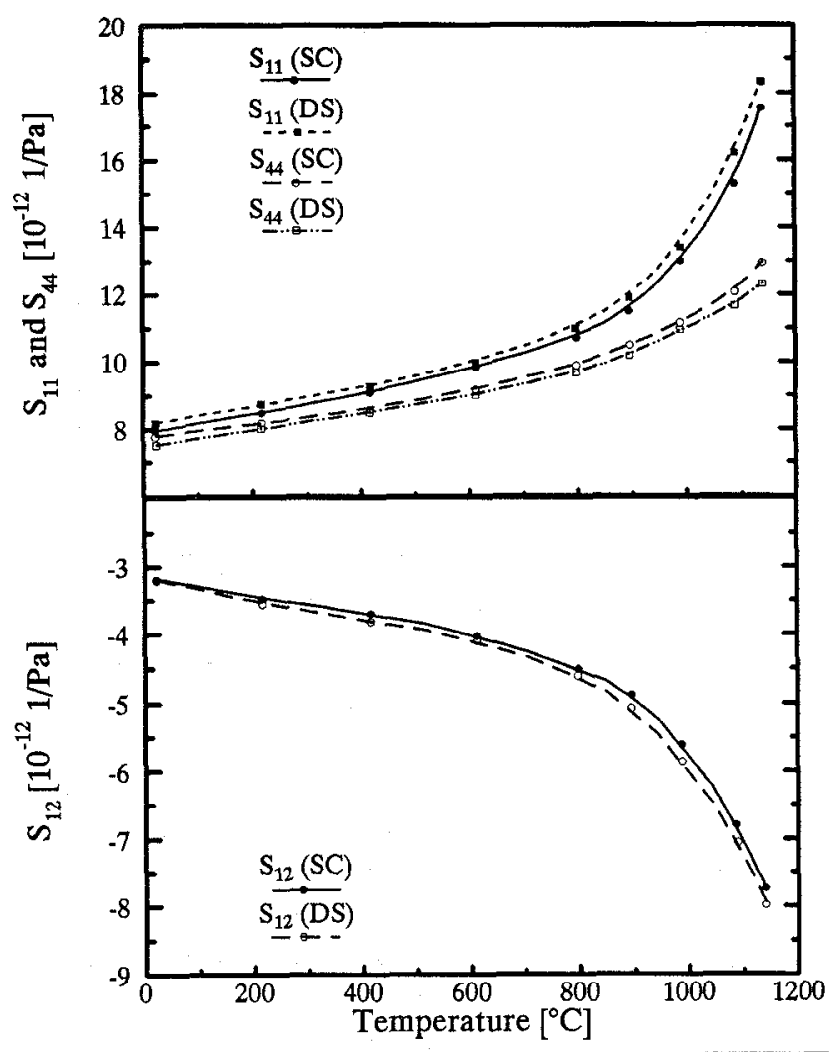

Figure 12: Elastic constants $S_{11}, S_{44}$ and $S_{12}$ for IN $738 \mathrm{LC}$, determinated from single crystal and DS-material measurements.

In order to describe the elastic behavior of an anisotropic material the direction-independent elastic single crystal constants (compliances $S_{i j}$ or stiffnesses $C_{i j}$ ) must be known. In the case of textured material the elastic polycrystal constants $\left(S_{\mathrm{ij}}^{\mathrm{pc}}\right.$ and $\left.C_{\mathrm{ij}}^{\mathrm{pc}}\right)$ are needed. They can be calculated from the single crystal constants and the orientation distribution function (ODF).

The determination of the elastic constants from resonance measurements of single crystals and textured materials by regression and by Finite Element methods were presented. All methods require measurements of the elastic properties on specimens prepared with different orientations of single crystals or with their axes at different angles to the direction of solidification, recrystallization or rolling in textured materials. These methods were applied to monocrystalline and textured Nickel-base alloys (SRR 99, CMSX-6, CMSX-4, IN 738 LC). The good agreement of the results from different methods and materials with different anisotropic behaviour demonstrate convincingly the efficiency and the usefulness of the regression and FE methods for the determination of the elastic single crystal constants.

Experiences with these methods for different materials show that a strong direction dependence of the elastic properties in the textured materials is a fundamental requirement for a successful application of the presented methods.

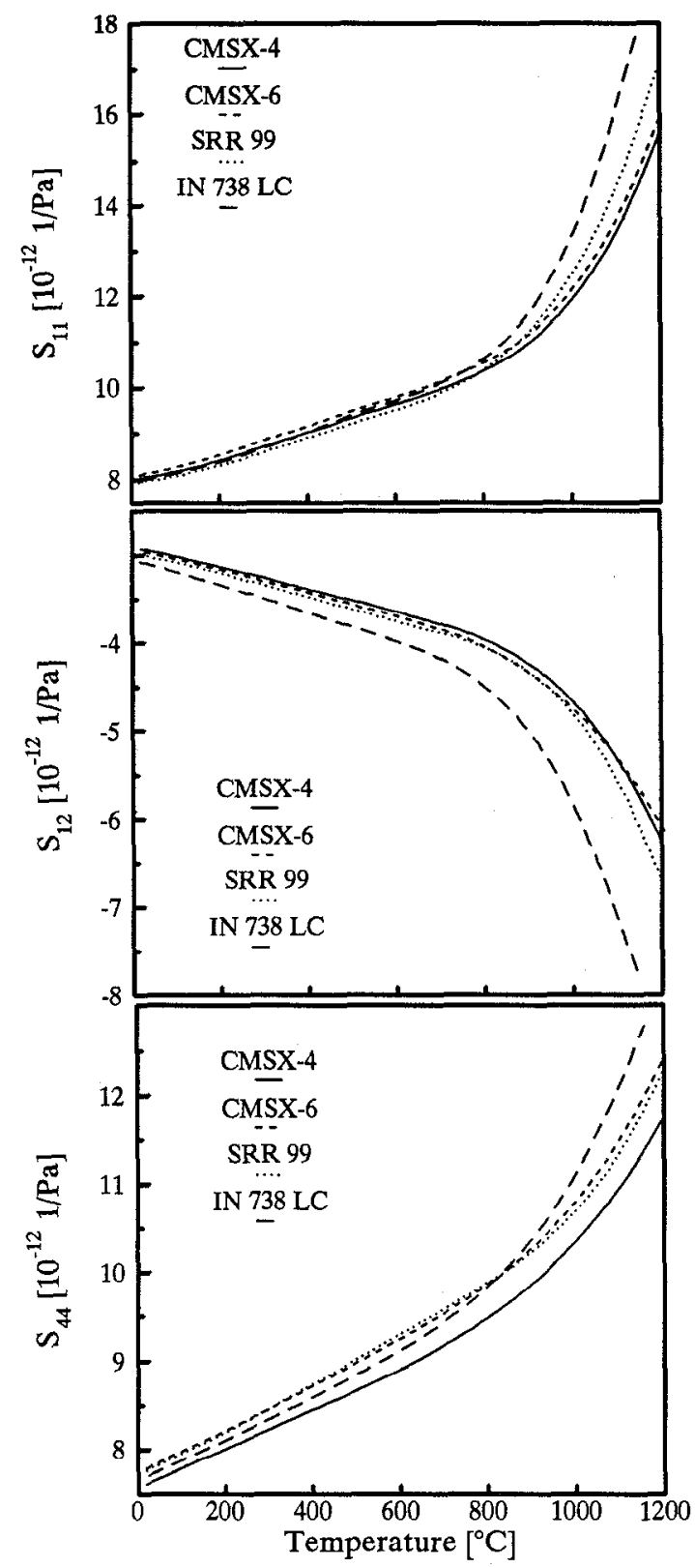

Figure 13: Comparison of the elastic compliances of the Nickelbase alloys CMSX-4, CMSX-6, SRR 99 and IN 738 LC.

\section{Acknowledgements}

The authors are grateful to the Forschungsgemeinschaft Verbrennungskraftmaschinen (FVV), the Arbeitsgemeinschaft Industrieller Forschungsvereinigungen (AIF) and the Deutsche Forschungsgemeinschaft (DFG) for the financial support of this work. 


\section{$\underline{\text { References }}$}

1. E. Goens, "Über die Bestimmung des Elastizitätsmoduls von Stäben mit Hilfe von Biegeschwingungen," Annalen der Physik 11 (1931), 6, 649-678.

2. J. Spinner and W.E. Tefft, "A method for determinating mechanical resonance frequencies and for calculating elastic moduli from these frequencies," Proc. ASTM 61 (1961), 1229-1238.

3. G. Pickelt, "Equations for computing elastic constants from flexural and torsional resonant frequencies of vibration of prisms and cylinders," Proc. ASTM 45 (1945), 846-865.

4. W. Voigt, Lehrbuch der Kristallphysik (Leipzig: Tcubncr, 1928).

5. J.F. Nye, Physical Properties of Crystals, Oxford University Press, New York, 1960.

6. R.F.S. Hearmon, "The elastic constants of anisotropic materials," Rev. Modern Physics, 18 (1946), 409-440.

7. E. Goens, "Über die Biegungs- und Drillungsschwingungen eines dünnen kreiszylindrischen Kristallstabes von beliebiger kristallographischer Orientierung," Annalen der Physik, 15 (1932), 45.5-484.

8. A. Reuss, "Berechnung der Fließgrenze von Mischkristallen auf Grund der Plastizitätsbedingungen für Einkristalle", Zeitschrift für angewandte Mathematik und Mechanik, 9 (1929), 49-58.

9. R. Hill, "The elastic behavior of a crystalline aggregate", Proc. Phys. Soc., A65 (1952), 349-354.

10. H.-J. Bunge, Mathematische Methoden der Texturanalyse (Berlin: Akademie Verlag, 1969).

11. R.A. Adamesku et al., "Invarianten der Anisotropie elastischer Eigenschaften von texturierten kubischen Metallen," Zeitschrift für Metallkunde, 76 (1985), 11, 747-749.

12. A. Bertram et al., "Bestimmung der elastischen Konstanten anisotroper Festkörper mittels FE-Simulation der Eigenschwingungen," Zeitschrift für angewandte Mathematik und Mechanik, 70 (1990), 322-323.

13. ADINA Users Manual, ADINA R\&D, Inc., 71 Elton Avenue Watertown, MA 02172 USA, 1990.

14. J.J. Moré, B.S. Garbow and K.E. Hillstrom, "User Guide for MINPACK-1," (Report ANL-80 74, Argonne National Laboratory, Argonne, IL, 1980).
15. A. Bertram et al., "Identification of Elastic Constants and Orientation of Single Crystals by Resonance Measurements and FE-Analysis," Special Issue of Int. Journal of Computer Applications in Technology, 7 (1994), 3/4, 285-292.

16. J. Han et al., "Identification of Crystal orientation by Resonance Measurements, Zeitschrift für angewandte Mathematik und Mechanik, 74 (1994), 4, 138-143.

17. U. Bayerlein and H.-G. Sockel, "Determination of single crystal elastic constants from DS- and DR-Ni-based superalloys by a new regression method between $20^{\circ} \mathrm{C}$ and $1200^{\circ} \mathrm{C}$," In: Superalloys 1992, Proc. of the Seventh Internat. Symposium on Superalloys, S.D. Antolovich et al. (eds.), TMS, Warrendale, PA., USA, 1992, 599-608.

18. J. Han et al., "Identification of Elastic Constants of Directionally Solidified Superalloys based on Resonance Measurement and FE-Analysis," In: Procceed. of the Academia Sinica Conference on Scientific and Engineering Computing, Beijing, China, Aug. 16-21, 1992 (1993).

19. I. Han et al., "Identification of Elastic Constants of Alloys with Sheet and Fibre Textures Based on Resonance Measurements and FE-Analysis," Mat. Sci. Eng.A, 191 (1995), 105-111.

20. W. Hermann and H.-G. Sockel, "Investigation of the HighTemperature Damping of the Nickel-Base Superalloy CMSX-4 in the kHz-Range," (Paper presented at the International Symposium on $\mathrm{M}^{3} \mathrm{D}$ III: Mechanics and Mechanisms of Material Damping, Norfolk, Virginia, USA, 15.-17.11.1995).

21. V. Sass, W. Schneider and H. Mughrabi, "On the Orientation Dependence of the Intermediate-Temperature Creep Behaviour of a Monocrystalline Nickel-Base Superalloy," Scripta Metallurgica et Materialia, 31, (1994), 7, 885-890.

\section{Appendix}

Calculation of the elastic polycrystal constants after Voigt and Reuss in the case of fiber-textured material exhibiting cubic lattice structure:

$$
\begin{aligned}
S_{11}^{R} & =S_{11}-0,4 S+3 a C_{4}^{1} S \\
S_{33}^{R} & =S_{11}-0,4 S+8 a C_{4}^{1} S \\
S_{12}^{R} & =S_{12}+0,2 S+a C_{4}^{1} S \\
S_{13}^{R} & =S_{12}+0,2 S-4 a C_{4}^{1} S \\
S_{44}^{R} & =S_{44}+0,8 S-16 a C_{4}^{1} S
\end{aligned}
$$




$$
\begin{aligned}
& C_{11}^{V}=C_{11}-0,4 C+3 a C_{4}^{1} C \\
& C_{33}^{V}=C_{11}-0,4 C+8 a C_{4}^{1} C \\
& C_{12}^{V}=C_{12}+0,2 C+a C_{4}^{1} C \\
& C_{13}^{V}=C_{12}+0,2 C-4 a C_{1}^{1} C \\
& C_{44}^{V}=C_{44}+0,2 C-4 a C_{4}^{1} C
\end{aligned}
$$

$$
\begin{aligned}
& \text { where: } \\
& a=0,006155 \\
& S=S_{11}-S_{12}-S_{44} / 2 \\
& C=C_{11}-C_{12}-2 C_{44} \\
& C_{4}^{1} \text { : coefficient of the ODF. }
\end{aligned}
$$

Calculation of the elastic stiffnesses $C_{11}, C_{12}$ and $C_{44}$ from the compliances $S_{11}, S_{12}$ and $S_{44}$ for cubic lattice structure:

$$
C_{11}=\frac{S_{11}+S_{12}}{\left(S_{11}-S_{12}\right) \cdot\left(S_{11}+2 S_{12}\right)},
$$

$$
\begin{gathered}
C_{12}=\frac{-S_{12}}{\left(S_{11}-S_{12}\right) \cdot\left(S_{11}+2 S_{12}\right)}, \\
C_{44}=\frac{1}{S_{44}} .
\end{gathered}
$$

